\title{
Mate-location failure, the Allee effect, and the establishment of invading populations
}

\author{
Takehiko Yamanaka · Andrew M. Liebhold
}

Published online: 13 May 2009

(C) The Society of Population Ecology and Springer 2009

In recent years, increased global trade and travel have provided potent invasion pathways for ever-increasing numbers of alien species. Although many species from distant parts of the world have increased productivity and taken on critical roles in agriculture, horticulture, forestry, and aquacultural industries, many other alien species have had serious deleterious effects on these same industries as well as on human health (Pimentel et al. 2000). Additionally, invasions by many non-indigenous species are known to negatively affect important ecological processes and properties in a variety of natural ecosystems (Mack et al. 2000; McNeely et al. 2001).

The immense impacts of invading species provide ample motivation for undertaking measures to prevent more species from establishing. Though prevention of the arrival of new species is often a desirable option, it may not always be possible to shut down all invasion pathways (Lodge et al. 2006). In cases where a newly arrived population is considered to pose a considerable risk, there may be justification to attempt eradication, i.e., the total elimination of a species over a given area. Large-scale eradication programs are often complex, involving both government agencies and public stakeholders (Myers et al. 1998). Eradication is much more likely to be successful if it is carried out in the early phase of an invasion rather than after a species has been present for an extended period

T. Yamanaka $(\square)$

Biodiversity Division, National Institute for Agro-Environmental

Sciences, 3-1-3 Kannondai, Tsukuba, Ibaraki

305-8604, Japan

e-mail: apple@affrc.go.jp

A. M. Liebhold

USDA Forest Service, Northern Research Station,

180 Canfield St., Morgantown, WV 26505, USA
(Wittenberg and Cock 2001). Given the difficulty of eradication as well its critical importance, it is vital that the population processes operating during the invasion process be understood and considered when formulating a strategy for achieving eradication (Liebhold and Tobin 2008).

Perhaps the single most important population process that affects establishment success is the Allee effect, which refers to the phenomenon of increasing per capita population growth with increasing density (Taylor and Hastings 2005; Courchamp et al. 2008). The concept of the Allee effect is not new: it originates from observations made by Warder Allee in the 1930s that survival and reproduction are often limited by a lack of conspecifics, and that this can lead to population decline at low densities (Allee 1931). This effect, probably one of the most exciting concepts in ecology, was long neglected but more recently re-discovered because of its profound implications for a variety of problems. Although Allee's concept was first resurrected by conservation biologists because they recognized its importance to the persistence of rare and endangered species (e.g., Lande 1987; Dennis 1989), applied ecologists eventually began to realize that the Allee effect has important implications for both the establishment and eradication of invasive alien species (Hopper and Roush 1993; Yoshimura et al. 1999; Liebhold and Bascompte 2003).

Several factors are known to cause the Allee effect in low-density populations: these include the absence of cooperation (e.g., cooperative feeding), genetic inbreeding, and predator satiation. However, the most prevalent cause of Allee dynamics is the failure of mates to locate each other at low population densities (Courchamp et al. 1999; Taylor and Hastings 2005). At low densities, populations may likely decline because of mate-location failure, but as populations increase, growth rates increase as individuals 
more easily encounter mates. The Allee effect may be intensified by the spatial isolation of founding individuals (Berec et al. 2001) and by temporal asynchrony in the development of the two sexes (Calabrese and Fagan 2004; Robinet et al. 2007). There are many other factors that may affect the strength of the Allee effect arising from matelocation failure, and this is a very active area of research.

Given the many recent important advances in understanding the role of the Allee effect in invading populations, we present here a special issue entitled "Matelocation failure, the Allee effect, and the establishment of invading populations". We invited nine papers that encompass a range of approaches, including reviews of precedent works, empirical investigations of natural systems, theoretical inquiries of new scientific hypotheses, and practical explorations of strategies for managing invasions. Two papers provide overviews of the ubiquity of the Allee effect among populations of various types of organisms. Kramer et al. (2009) address the prevalence of the effect among different animal taxa by comparing empirical results provided in 75 papers. They find evidence for demographic Allee effects in nearly all taxa for which data are available. Furthermore, they find that these demographic Allee effects arise most frequently from mate limitation in invertebrate populations, and from predatorprey interactions in vertebrate populations. Another overview of the prevalence of the Allee effect is provided by Gascoigne et al. (2009) who approach their synthesis from an evolutionary standpoint. They conclude that evolution may act to diminish the frequency of mate-location failure through selection either for more efficient mate-finding mechanisms or for behaviors, such as aggregation, that avoid low densities. They hypothesize that, as a result of this evolutionary pressure, component Allee effects due to mate-location failure may not be common in natural systems.

Three groups contribute empirical evidence of component and demographic Allee effects in specific populations. Tobin et al. (2009) review the literature on the Allee effect arising from mate-location failure in gypsy moth populations. This is a system in which the population biology is understood relatively well and which has been extensively monitored for decades in North America. As such it provides an exceptional opportunity for observing the Allee effect in field populations and understanding the effect on invasion success. Fauvergue and Hopper (2009) took a novel approach to investigate the existence of the Allee effect caused by mate-location failure by observing the consequences of intentional introductions of a parasitoid wasp, Aphelinus asychis, as a biological control. Contrasting two population sizes, high and low densities, they concluded that there was a significant demographic Allee effect in wasp populations. However, they also found that wasps did not suffer from a mate-finding Allee effect. They proposed that a number of behavioral and life-history features of many parasitoids (e.g., a haplo-diploid sex determination mechanism) could protect them from matefinding Allee effects. Though his study was not based on observation of a natural system, Takasu (2009) gained considerable insight into the system of pine wilt disease in Japan by applying an individual-based model. The disease is caused by a nematode, which is vectored by the Japanese pine sawyer beetle. He showed that an Allee effect can arise in beetle dynamics as a result of the necessity of beetles to make contact with a pine tree at least twice in order to successfully reproduce.

Two theoretical studies make important contributions to rather general aspects of the Allee effect. Sato (2009) constructs a spatially explicit metapopulation model in which immigrants only colonize from the nearest neighboring patches. His ecologically meaningful model indicates that the entire metapopulation does not have an Allee threshold for initial population size even if each local population is influenced by the Allee effect. In addition, he finds that the metapopulation extinction threshold becomes lower than that estimated by the standard and classic metapopulation model of Levins (1969). As many invasive species characteristically colonize patchy host resources in the field, his findings have important implications for managing such species. Takimoto (2009) constructs a stochastic differential equation of an invasive species with the Allee effect. Using this tractable but biologically realistic model, he explores which indicator will have the most diagnostic value for a sudden shift from low to high population levels. He finds that the standard deviation of population abundance during a period of low abundance is a useful predictor of an impending demographic upsurge.

To elucidate direct countermeasures against invasive species, Yamanaka and Liebhold (2009) utilized a spatially implicit modeling approach which they applied to three different eradication strategies: mass-trapping, matingdisruption, and sterile male release. Using their generalized mechanistic approach, it was possible for them to quantify the impact of these strategies on the mate-finding Allee effect and to compare the effectiveness of the different approaches for eradication of insects with varying life history traits. Boukal and Berec (2009) also explored implications of the interaction between the Allee effect and anthropogenic intervention (i.e., pest-control) using a series of simple differential equations. They concluded that, in many situations, by combining two or more management strategies, invasive species can be more easily eliminated than by applying only a single strategy.

By facilitating this special issue, we aim to improve the general understanding of process operating during the early 
establishment phase of biological invasions. Some pessimistic ecologists may complain that there has been little progress in our ability to identify general 'rules' that govern the processes of invasion that have practical predictive value, despite 40 years of study (Bright 1998). We, however, feel that current theories on the Allee effect provide useful insight into practical strategies for managing invasions, but applied information also provides some insight into basic theories. We intend for this special issue to not only promote a deeper understanding of the mechanisms operating during biological invasions, but also to evoke new ideas for future theoretical efforts and empirical investigations of invasions and their management.

\section{Cover photo descriptions}

1 (upper left): a gypsy moth male. Tobin et al. (2009) review the invasion of gypsy moth in North America. Photo by Louis-Michel Nageleisen, Département de la Santé des Forêts, Bugwood.org. 2 (upper right): The first fabled Allee effect: the fate of humanity hangs in the balance as Adam and Eve search for each other in the sparsest of populations. Illustration credit: Mike Blackburn. 3 (lower left): the photo shows the parasitoid wasp Aphelinus asychis Walker (Hymenoptera: Aphelinidae) ovipositing in the Russian wheat aphid Diuraphis noxia (Modvilko) (Hemiptera: Aphididae). Aphelinus asychis was introduced during the 1990s in the United States for the biological control of $D$. noxia, a major pest on small grains (wheat, barley, etc.). Fauvergue and Hopper (2009) analyzed these introductions, mate-finding behavior, and the dynamics of small introduced populations. 4 (lower right): the green anole (Anolis carolinensis) preying on an endemic cicada (Meimuna boninensis) of the Ogasawara Islands, Japan. Photo courtesy of Mitsuhiko Toda, Japan Wildlife Research Center.

\begin{abstract}
Acknowledgments The original idea of this special feature was evoked in the discussion between T Yamanaka and AM Liebhold during T.Y.'s long-term exchange program in Pennsylvania State University founded by the National Institute for Agro-Environmental Sciences. We greatly thank Kazunori Sato (Shizuoka University) not only for his contribution to our special feature but also for his invaluable assistance during the editorial processes. We also thank You Iwasa in Kyushu University and Atsushi Yamauchi in Kyoto University for their assistance during the early phase of planning this special section.
\end{abstract}

\section{References}

Allee WC (1931) Animal aggregations. University of Chicago Press, Chicago

Berec L, Boukal DS, Berec M (2001) Linking the Allee effect, sexual reproduction, and temperature-dependent sex determination via spatial dynamics. Am Nat 157:217-230
Boukal DS, Berec L (2009) Modelling mate-finding Allee effects and populations dynamics, with applications in pest control. Popul Ecol 51. doi: 10.1007/s10144-009-0154-4

Bright C (1998) Life out of bounds-Bioinvasion in a borderless world. Norton, New York

Calabrese JM, Fagan WF (2004) Lost in time, lonely, and single: reproductive asynchrony and the Allee effect. Am Nat 164:2537

Courchamp F, Clutton-Brock TH, Grenfell BT (1999) Inverse density dependence and the Allee effect. Trends Ecol Evol 14:405-410

Courchamp F, Berec L, Gascoigne J (2008) Allee effects in ecology and conservation. Oxford University Press, New York

Dennis B (1989) Allee effects: population growth, critical density, and the chance of extinction. Nat Res Model 3:481-538

Fauvergue X, Hopper KR (2009) French wasps in the New World: experimental biological control introductions reveal a demographic Allee effect. Popul Ecol 51. doi: 10.1007/s10144-0090147-3

Gascoigne J, Berec L, Gregory S, Courchamp F (2009) Dangerously few liaisons: a review of mate-finding Allee effects. Popul Ecol 51. doi: 10.1007/s10144-009-0146-4

Hopper KR, Roush RT (1993) Mate finding, dispersal, number released, and the success of biological control introductions. Ecol Entomol 18:321-331

Kramer AM, Dennis B, Liebhold AM, Drake JM (2009) The evidence for Allee effects. Popul Ecol 51. doi: 10.1007/s10144-009$0152-6$

Lande R (1987) Extinction thresholds in demographic models of territorial populations. Am Nat 130:624-635

Levins R (1969) Some demographic and genetic consequences of environmental heterogeneity for biological control. Bull Entomol Soc Am 15:237-240

Liebhold AM, Bascompte J (2003) The Allee effect, stochastic dynamics and the eradication of alien species. Ecol Lett 6:133-140

Liebhold AM, Tobin PC (2008) Population ecology of insect invasions and their management. Annu Rev Entomol 53: 387-408

Lodge DM, Williams S, MacIsaac HJ, Hayes KR, Leung B, Reichard S, Mack RN, Moyle PB, Smith M, Andow DA, Carlton JT, McMichael A (2006) Biological invasions: recommendations for U.S. policy and management. Ecol Appl 16:2035-2054

Mack RN, Simberloff D, Lonsdale WN, Evans H, Clout M, Bazzaz FA (2000) Biotic invasions: causes, epidemiology, global consequences, and control. Ecol Appl 10:689-710

McNeely JA, Mooney HA, Neville LE, Schei P, Waage JK (2001) A global strategy on invasive alien species. IUCN, Gland, Switzerland

Myers JH, Savoie A, van Randen E (1998) Eradication and pest management. Annu Rev Entomol 43:471-491

Pimentel D, Lach L, Zuniga R, Morrison D (2000) Environmental and economic costs of nonindigenous species in the United States. BioScience 50:53-65

Robinet C, Liebhold AM, Gray DR (2007) Variation in developmental time affects mating success and Allee effects. Oikos 116:1227-1237

Sato K (2009) Allee threshold and extinction threshold for spatially explicit metapopulation dynamics with Allee effects. Popul Ecol 51. doi: 10.1007/s10144-009-0156-2

Takasu F (2009) Individual-based modeling of the spread of pine wilt disease: vector beetle dispersal and the Allee effect. Popul Ecol 51. doi: 10.1007/s10144-009-0145-5

Takimoto G (2009) Early warning signals of demographic regime shifts in invading populations. Popul Ecol 51. doi: 10.1007/ s10144-009-0148-2

Taylor CM, Hastings A (2005) Allee effects in biological invasions. Ecol Lett 8:895-908 
Tobin PC, Robinet C, Johnson DM, Whitmire SL, Bjørnstad ON, Liebhold AM (2009) The role of Allee effects in gypsy moth, Lymantria dispar (L.), invasions. Popul Ecol 51. doi: 10.1007/ s10144-009-0144-6

Wittenberg R, Cock MJW (2001) Invasive alien species: a toolkit of best prevention and management practices. CAB International, Wallingford
Yamanaka T, Liebhold AM (2009) Spatially implicit approaches to understanding the manipulation of mating success for insect invasion management. Popul Ecol 51. doi: 10.1007/s10144009-0155-3

Yoshimura A, Kawasaki K, Takasu F, Togashi K, Futai K, Shigesada N (1999) Modeling the spread of pine wilt disease caused by nematodes with pine sawyers as vector. Ecology 80:1691-1702 